\title{
Insulin release by glucose anomers in a rat model of non-insulin-dependent diabetes
}

\author{
A. Niki ${ }^{1}, \mathrm{H} . \mathrm{Niki}^{1}$, I. Niki ${ }^{2}$ and Y.Kunoh ${ }^{3}$ \\ ${ }^{1}$ Department of Internal Medicine, Aichigakuin University School of Dentistry, \\ ${ }^{2}$ Third Department of Internal Medicine, University of Nagoya School of Medicine and \\ ${ }^{3}$ Maruko Pharmaceutical Co., Ltd., Nagoya, Japan
}

\begin{abstract}
Summary. The effects of the $\alpha$ and $\beta$ anomers of D-glucose on insulin release were studied in a rat model of non-insulindependent diabetes, which was induced by streptozotocin injection at 2 days of age. Glucose tolerance of the streptozotocin-treated rats at 8-10 weeks of age was mildly diabetic. Insulin release from the isolated perfused pancreas of the diabetic rats in response to $10 \mathrm{mmol} / 1 \alpha$-D-glucose was
\end{abstract}

markedly impaired, while insulin response to $10 \mathrm{mmol} / 1 \beta$ D-glucose in the diabetic pancreas was only slightly reduced as compared to that in the control pancreas.

Key words: Insulin release, glucose anomers, streptozotocin, neonatal rat, non-insulin-dependent diabetes, pancreas perfusion, pancreatic B cell.
The $\alpha$ anomer of $\mathrm{D}$-glucose is known to be more potent than the $\beta$ anomer in stimulating insulin release from the pancreas of normal animals as well as humans (for review see [1]). In non-obese, Type 2 (noninsulin-dependent) diabetic patients, glucose-induced insulin release is markedly reduced, even though the insulin response to nonglucose secretagogues is preserved [2]. However, it has not been elucidated whether the pancreatic $B$ cell in Type 2 diabetic patients discriminates the $\alpha$ and $\beta$ anomers of D-glucose. Rovira et al. [3] recently reported in an abstract form that no preferential insulin response to $\alpha$-D-glucose was observed in some, but not all, Type 2 diabetic patients. The finding suggests that the ability of the pancreatic B cell to discriminate D-glucose anomers may be diminished in certain forms of non-insulin-dependent diabetes. An experimental model of Type 2 diabetes has been developed in the rat, which is obtained by a neonatal streptozotocin injection and is later on characterised by low insulin response to glucose $[4,5]$. We have studied the effect of the $\alpha$ and $\beta$ anomers of D-glucose on insulin release in this rat model using the isolated perfused pancreas.

\section{Materials and methods}

Male Sprague-Dawley rats were injected intraperitoneally at 2 days of age with $90 \mathrm{mg} / \mathrm{kg}$ streptozotocin (Sigma, St. Louis, Mo, USA) in $0.1 \mathrm{~mol} / 1$ citrate buffer, $\mathrm{pH} 4.5$, as described by Bonner-Weir et al. [4]. Control rats from the same litters received the equivalent volume of citrate buffer. Oral glucose tolerance tests $(11.1 \mathrm{mmol}$ glucose $/ \mathrm{kg}$ body weight) were performed at $8-10$ weeks of age after an over- night fast. Blood was sampled from the tail vein before, and 30,60 and $120 \mathrm{~min}$ after glucose administration with the use of a catheter. The perfusion experiments were carried out in the fed state within 2 weeks after the glucose tolerance tests. The technique of perfusing the isolated pancreas with hexose anomers was as described previously [6]. The basal perfusion medium consisted of $45 \mathrm{~g} / 1$ Destran $\mathrm{T}$ 70 (Pharmacia, Uppsala, Sweden) and $5 \mathrm{~g} / 1$ bovine serum albumin (fraction V; Armour, Kankakee, Ill, USA) in Krebs-Ringer bicarbonate buffer $(\mathrm{pH} 7.4)$ equilibrated with a mixture of $95 \% \mathrm{O}_{2}$ and $5 \%$ $\mathrm{CO}_{2}$. The $\alpha$ or $\beta$ anomer of D-glucose (Sigma) was rapidly dissolved in ice-cold basal medium just before use in a concentration of $10 \mathrm{mmol} / 1$. The ice-cold perfusion solutions were warmed up to $37^{\circ} \mathrm{C}$ immediately before reaching the pancreas in a heating coil immersed in a water bath. Flow rates were kept at approximately $3.0 \mathrm{ml} / \mathrm{min}$ by a constant gas $\left(\mathrm{O}_{2}: \mathrm{CO}_{2}, 95: 5\right)$ pressure of about $70 \mathrm{~cm} \mathrm{H}_{2} \mathrm{O}$. The pancreas was preperfused with the basal medium containing $1.67 \mathrm{mmol} / 1$ equilibrated $\mathrm{D}$-glucose for $20 \mathrm{~min}$, and then perfused with either the $\alpha$ or $\beta$ anomer of D-glucose for $20 \mathrm{~min}$. Of the 10 diabetic or 10 control rats used, 5 rats were tested with the $\alpha$ anomer and other 5 tested with the $\beta$ anomer.

Blood glucose was determined by the $o$-toluidine-glacial acetic method [6]. Insulin in the perfusate was measured by solid phase radioimmunoassay (Insulin Riabead; Dainabot, Tokyo, Japan) using rat insulin as the standard (Novo, Bagsvaerd, Denmark).

\section{Statistical analysis}

All results were expressed as mean \pm SEM and statistical analysis was performed using the unpaired, two-tailed Student's t-test.

\section{Results}

Figure 1 shows the blood glucose curves during the oral glucose tolerance tests in the streptozotocin-treated diabetic rats and age-matched control rats. Fasting 
blood glucose levels were not significantly different between the two groups of rats. After the glucose load, however, the blood glucose levels in the diabetic rats were significantly higher than those in the controls, and the mean maximal level reached approximately $16.7 \mathrm{mmol} / \mathrm{l}$. The body weight of the diabetic rats at time of the perfusion experiment was not significantly different from that of the control rats $(348.8 \pm 9.8$ vs $358.5 \pm 10.2 \mathrm{~g}$ ).

The effects of the $\alpha$ and $\beta$ anomers of D-glucose on insulin release from the isolated perfused pancreas are shown in Figure 2. In the control rats (Fig. 2 a), the $\alpha$ anomer of D-glucose at a concentration of $10 \mathrm{mmol} / \mathrm{l}$ evoked significantly higher insulin release than the same concentration of the $\beta$ anomer. The dominant ef-

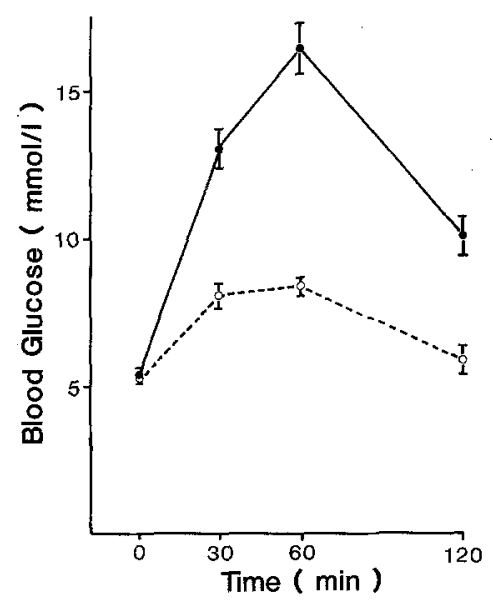

Fig. 1. Oral glucose tolerance test in control $\left(\mathrm{O}_{---} \mathrm{O}\right)$ and diabetic rats $(-)$ treated with streptozotocin at 2 days of age.Tests were performed at 8-10 weeks of age following an overnight fast. Each point represents the mean of 10 animals with SEM shown by the vertical line. Significant differences between control and diabetic rats in blood glucose levels were observed at 30,60 and $120 \mathrm{~min}(p<0.001)$ after oral administration of glucose $(11.1 \mathrm{mmol}$ glucose $/ \mathrm{kg}$ body weight) fect of the $\alpha$ anomer was observed both in the first and second phases of insulin release. In contrast, insulin response to $10 \mathrm{mmol} / 1 \alpha$-D-glucose in the diabetic rats was not significantly different from the response to $\beta$ D-glucose of $10 \mathrm{mmol} / 1$ (Fig. 2b). The amount of insulin release during the 20 -min perfusion with $\alpha$-D-glucose in the diabetic rats was $30.6 \%$ of that in the control rats $(120.7 \pm 11.0$ vs $393.4 \pm 30.7 \mathrm{ng}, p<0.001)$, while that with $\beta$-D-glucose in the diabetic rats was $79.0 \%$ of that in the controls $(94.4 \pm 5.3$ vs $119.5 \pm$ $6.7 \mathrm{ng}, p<0.05$ ).

\section{Discussion}

Weir and co-workers $[4,5]$ reported that rats injected with streptozotocin at 2 days of age developed non-insulin-dependent diabetes with normal body weight at about 6 weeks of age. Their studies on the perfused pancreas of such diabetic rats at between 6 and 15 weeks showed that insulin release in response to glucose was markedly impaired, whereas insulin release was well preserved in response to nonglucose secretagogues, such as arginine or isoproterenol.

In the present experiment using the same animal model, the markedly impaired insulin response in the diabetic pancreas was observed when the pancreas was perfused with the $\alpha$ anomer of D-glucose, while the insulin response to the $\beta$ anomer was only slightly reduced in the diabetic pancreas as compared to that in the control pancreas. Thus, the impaired insulin response to glucose in this diabetic rat model is considered to result mainly from lowered sensitivity of the pancreatic B cell to the $\alpha$ anomer of D-glucose. Insulin responses to tolbutamide in the diabetic and control pancreata did not significantly differ in our hands (data notshown), though controversial findings have been

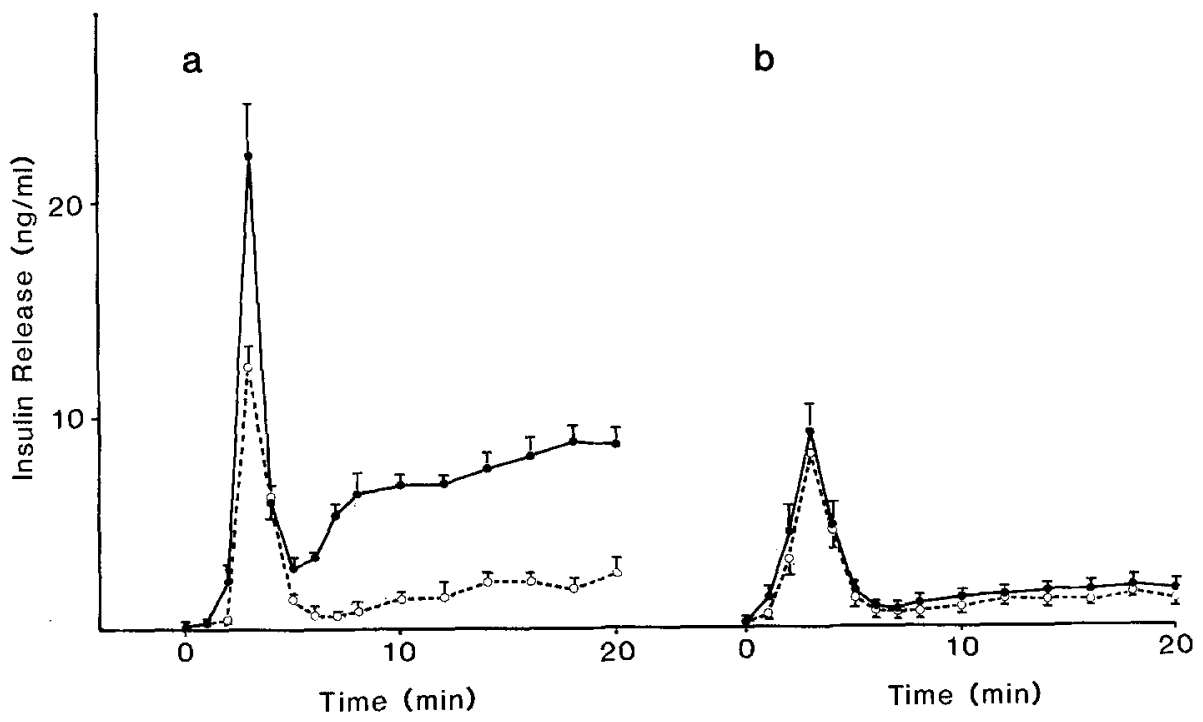

Fig. 2a and b. Effects of the $\alpha(-\infty)$ and $\beta(O--O)$ anomers of D-glucose on insulin release from the isolated perfused pancreas of control (a) and diabetic rats that received streptozotocin at 2 days of age (b). After 20-min preperfusion with the basel medium containing $1.67 \mathrm{mmol} / 1$ equilibrated D-glucose, $\alpha$ - or $\beta$-D-glucose at a concentration of $10 \mathrm{mmol} / 1$ was introduced for $20 \mathrm{~min}$. Values represent mean $( \pm$ SEM) insulin levels $(n=5)$. Significant differences between insulin levels with $\alpha$ and $\beta$-D-glucose were observed in control rats (a) at $3 \mathrm{~min}$ and after $6 \mathrm{~min}(p<0.01)$; at 2 and $5 \min (p<0.05)$ 
reported as to insulin release in response to the agent in this kind of diabetic model, probably related to the severity of the diabetes $[5,7]$.

These findings suggest that the pancreatic B-cell function which is impaired in the diabetic rat model is related to the mechanism by which the $\mathrm{B}$ cell discriminates the $\alpha$ and $\beta$ anomers of D-glucose as a stimulator of insulin release; the mechanism is a matter of debate (for review see $[8,9]$ ). Most of the reports suggest that discrimination occurs at glycolytic enzyme(s) with the specificity for the $\alpha$ anomer; namely at glucokinase, phosphoglucose isomerase and/or phosphoglucomutase. A higher glycolytic flux of the $\alpha$ anomer is considered to result in a higher amount of insulin release in response to the $\alpha$ than the $\beta$ anomer. However, Colella et al. [10] recently reported that glucose utilisation in the pancreatic islets isolated from the diabetic rat model was similar or higher than in comparable control islets. Thus, they suggested that the glucose blindness of the diabetic islets might not be attributable to reduced glucose metabolism, but to an as yet undetermined defect(s) distal to glucose metabolism.

Though the mechanism responsible for lowering the sensitivity of the pancreatic B cell to the $\alpha$ anomer of D-glucose in this diabetic rat model remains unknown, the present finding may provide some insight into the pathophysiology of the pancreatic B cell in certain forms of non-insulin-dependent diabetes.

Acknowledgements. We thank Ms. F. Furuta, Aichigakuin University, for her technical and secretarial assistance.

\section{References}

1. Niki A, Niki H (1980) Hexose anomers, insulin release, and diabetes mellitus. Biomed Res 1: 189-206

2. Ward WK, Beard JC, Halter JB, Pfeifer MA, Porte DJr (1984) Pathophysiology of insulin secretion in non-insulin-dependent diabetes mellitus. Diabetes Care 7: 491-502

3. Rovira A, Garrote FJ, Valverde I, Malaisse WJ (1987) Anomeric specificity of D-glucose-induced insulin release in normal and diabetic subjects. Diabetes 36 [Suppl 1]: 165A

4. Bonner-Weir S, Trent DF, Honey RN, Weir GC (1981) Responses of neonatal rat islets to streptozotocin. Limited B-cell regeneration and hyperglycemia. Diabetes 30:64-69

5. Weir GC, Clore ET, Zmachinski CJ, Bonner-Weir S (1981) Islet secretion in a new experimental model for non-insulin-dependent diabetes. Diabetes 30: 590-595

6. Niki A, Niki H, Miwa I (1979) Effect of anomers of D-mannose on insulin release from perfused rat pancreas. Endocrinology 105: 1051-1054

7. Giroix M-H, Portha B, Kergoat M, Bailbe D, Picon L (1983) Glucose insensitivity and amino-acid hypersensitivity of insulin release in rats with non-insulin-dependent diabetes. A study with the perfused pancreas. Diabetes 32: 445-451

8. Malaisse WJ, Malaisse-Lagae F, Sener A (1983) Anomeric specificity of hexose metabolism in pancreatic islets. Physiol Rev 63: 773-786

9. Meglasson MD, Matschinsky FM (1984) New perspectives on pancreatic islet glucokinase. Am J Physiol 246: E1-E13

10. Colella RM, May JM, Bonner-Weir S, Leahy JL, Weir GC (1987) Glucose utilization in islets of hyperglycemic rat models with impaired glucose-induced insulin secretion. Metabolism 36: 335-337

Received: 21 September 1987 and in revised form: 3 November 1987

Dr. A. Niki

Department of Internal Medicine

Aichigakuin University School of Dentistry

Suemori, Chikusa, Nagoya 464

Japan 